\title{
Estaquia caulinar de Rubus erythrocladus Mart. ex Hook.f. em diferentes concentrações de ácido indolbutírico
}

\author{
Júlio Tagliari Balestrin', Rodrigo Oliveira Lamb', Vinicius Ferrari', Juliana Marcia Rogalski' \\ ' Núcleo de Ciências Biológicas e Ambientais. Instituto Federal de Educação, Ciência e Tecnologia do Rio Grande do Sul (IFRS), \\ Campus Sertão. Sertão, RS, Brasil. E-mails: juliotbalestrin@gmail.com, rodrigo-lamb20I I@hotmail.com, viniferrari26I@gmail. \\ com, juliana.rogalski@sertao.ifrs.edu.br
}

Submetido em: 23 set. 2019. Aceito: 7 julho 2020. DOI: http://dx.doi.org/10.21674/2448-0479.63.193-197

\section{Resumo}

O arbusto Rubus erythrocladus Mart. ex Hook.f. (amora-verde) é uma espécie endêmica do Brasil e uma das plantas alimentícias não convencionais que apresenta grande potencial de uso, devido ao sabor agradável de seus frutos e às altas concentrações de flavonoides. O objetivo desse estudo foi avaliar o efeito de diferentes concentrações de AIB no enraizamento de estacas caulinares de $R$. erythrocladus. $O$ experimento foi realizado em casa de vegetação no IFRS Campus Sertão, durante o período de novembro de 2018 a janeiro de 2019. O delineamento experimental utilizado foi inteiramente casualizado, com seis concentrações (0, 500, 1.000, 2.000, 3.000 e $\left.4.000 \mathrm{mg} \mathrm{L}^{-1}\right)$ de AIB, cinco estacas por unidade experimental e quatro repetições, totalizando 120 estacas. As percentagens de sobrevivência e de enraizamento das estacas, o número de raízes e o comprimento da maior raiz foram avaliados após 60 dias da implantação do experimento. Os dados foram analisados através de análise de variância e as médias comparadas pelo teste de Tukey $(\alpha=0,05)$. O número de raízes e o comprimento da maior raiz foram avaliados através de estatísticas descritivas (média e desvio padrão). As estacas tratadas com AIB na concentração $1.000 \mathrm{mg} \mathrm{L}^{-1}$ apresentaram maior sobrevivência e enraizamento (60\%), maior número de raízes $(2,8 \pm 2,6)$ e maior comprimento de raiz $(6,5 \pm 2,5 \mathrm{~cm})$, diferindo estatisticamente dos demais tratamentos. A aplicação de AIB na concentração de $1.000 \mathrm{mg} \mathrm{L}^{-1}$ foi o melhor tratamento para a rizogênese de estacas caulinares de $R$. erythrocladus.

Palavras-chave: Amora-silvestre. PANC. Pequenos frutos. Propagação vegetativa.

\section{Abstract}

Stem cuttings of Rubus erythrocladus Mart. Ex Hook.f. at different concentrations of indolebutyric acid The shrub Rubus erythrocladus Mart. ex Hook.f. (amora-verde) is an endemic species from Brazil and one of the unconventional food plants, which has great potential for use due to pleasant taste of its fruits and high concentrations of flavonoids. The objective of this study was to evaluate the effect of different IBA concentrations on rooting of $R$. erythrocladus stem cuttings. The experiment was carried out under greenhouse at IFRS - Campus Sertão, from November 2018 to January 2019. The experimental design was completely randomized with six concentrations $\left(0,500,1,000,2,000,3,000\right.$ and 4,000 $\left.\mathrm{mg} \mathrm{L}^{-1}\right)$ IBA, with five cuttings per experimental unit and four replications, totaling 120 cuttings. Survival and cuttings rooting percentages, roots number and the largest root length were evaluated after 60 days of experiment implementation. Data were analyzed by analysis of variance and means 
compared by Tukey test $(\alpha=0.05)$. The number of roots and the length of the largest root were evaluated using descriptive statistics (mean and standard deviation). Cuttings treated with IBA at concentration $1000 \mathrm{mg} \mathrm{L}^{-1}$ showed higher survival and rooting $(60 \%)$, higher number of roots $(2.8 \pm 2.6)$ and length of the largest root $(6.5 \pm$ $2.5 \mathrm{~cm}$ ), differing statistically from other treatments. IBA application at the concentration of $\mathrm{I}, 000 \mathrm{mg} \mathrm{L}^{-1}$ was the best treatment for the rhizogenesis of stem cuttings of $R$. erythrocladus.

Keywords: Wild blackberry. Unconventional food plants. Small fruits. Vegetative propagation.

\section{Introdução}

O gênero Rubus (Rosaceae) apresenta grande diversidade de espécies, distribuídas no mundo inteiro, assim como vários tipos de frutos e pigmentações (DEIGHTON et al., 2000). Esse gênero possui cerca de 700 espécies, além de híbridos e muitas cultivares (HUANG; HU, 2009). No Brasil, ocorrem II espécies, sendo três delas endêmicas (SIMÃO-BIANCHINI, 20I5). As espécies com ocorrência no Brasil apresentam ampla distribuição em regiões de clima ameno, sendo comumente associadas às áreas montanhosas, embora possam ocorrer em outros ambientes, em menor frequência e abundância (BARCELOS; HEIDEN, 20I5).

Inúmeras são as aplicações de Rubus, sendo possível a utilização de praticamente todas as partes da planta. Os frutos são consumidos in natura ou processados (geleias, sorvetes e bolos), além de serem muito atraentes para a fauna. As folhas de algumas espécies de Rubus são utilizadas em chás, devido às propriedades fitoterápicas apresentadas (HUMMER, 2010; CARPANEZZI et al., 2019). No Brasil, apesar do uso alimentar e medicinal de Rubus ter sido documentado há muito tempo, nenhuma espécie nativa foi totalmente domesticada (BARCELOS; HEIDEN, 20I5; CARPANEZZI et al., 2019).

A espécie Rubus erythrocladus Mart. ex Hook.f. é conhecida desde a época do descobrimento do Brasil, seus frutos denominados na época de apé, já despertavam o interesse dos colonizadores (HUE et al., 2008). Também é conhecida popularmente como: amora-verde, amora-branca, amora-do-mato ou capinuriba-verde. É endêmica do Brasil, com ocorrência nos Biomas Mata Attântica (Floresta Ombrófila Mista e Campos) e Cerrado, ocorrendo nas regiões Sul (Rio Grande do Sul, Santa Catarina e Paraná) e Sudeste (São Paulo, Rio de Janeiro e Minas Gerais) do Brasil (SIMÃO-BIANCHINI, 20I5). É considerada uma das três espécies mais importantes do gênero Rubus na região Sul do Brasil (REITZ; KLEIN, 1996).

A planta consiste em um arbusto pequeno, chegando até dois metros de altura, tendo ramos frouxos, vermelhos e armados de numerosos acúleos, suas folhas inferiores 5 -folioladas e as superiores 3 -folioladas, folíolos ovado-lanceolados, estreitos, acuminados, flores com coloração branca e pequenas, dispostas em panículas terminais, fruto com coloração verde, subglobosos (PIO CORRÊA, 1984). Devido ao sabor agradável de seus frutos essa espécie está listada nas plantas alimentícias não convencionais (PANC), apresentando grande potencial de utilização no futuro (KINUPP; LORENZI, 20I4). Além disso, a presença dos flavonoides kaempferol e quercetina em $R$. erythrocladus foi comprovada em quantidades superiores as demais espécies analisadas deste gênero (TALLINI et al., 20I5).

Dentre as técnicas de propagação do gênero Rubus a mais difundida é a estaquia (caulinar e radicular), sendo possível ainda, a utilização de rebentos e cultura de tecidos (ANTUNES; RASSEIRA, 2004). A auxina sintética ácido indolbutírico (AIB) é uma grande aliada no processo de enraizamento de estacas de espécies frutíferas, devido a sua capacidade de acelerar e uniformizar o processo de emissão de raízes adventícias (HAN; ZHANG; SUN, 2009).

A propagação vegetativa de Rubus, através de estacas caulinares, é realizada durante o inverno (período de dormência das gemas), devido à grande quantidade de material obtido por ocasião da poda (MAIA; BOTELHO, 2008). Entretanto, estacas caulinares de espécies silvestres de Rubus apresentam percentagens de enraizamento menores que as comerciais quando submetidas aos mesmos protocolos de propagação (PATTO, 20I3). Conforme Bueno, Biasi e Tofanelli (20l8), estacas de R. erythrocladus são difíceis de enraizar e faltam estudos publicados sobre sua propagação.

Diante do exposto, o presente estudo teve como objetivo avaliar o efeito de diferentes concentrações de AIB no enraizamento de estacas caulinares de $R$. erythrocladus, visando a otimização da propagação por estaquia. 


\section{Material e Métodos}

O experimento foi conduzido em casa de vegetação no Instituto Federal de Educação, Ciência e Tecnologia do Rio Grande do Sul (IFRS) - Campus Sertão (28 02' 42" S e 52 $16^{\circ}$ ' I7" W; altitude de 737 metros) sob condições controladas (temperatura de $25^{\circ} \mathrm{C}$ e irrigação via nebulização intermitente por 30 segundos a cada 30 minutos), no período de novembro de 2018 a janeiro de 2019.

Na segunda quinzena de novembro de 2018 , foram coletadas estacas de ramos lenhosos da porção mediana de plantas matrizes de $R$. erythrocladus, em uma pequena propriedade rural, do município de Getúlio Vargas, região Norte do Rio Grande do Sul.

Inicialmente as estacas caulinares foram padronizadas, com $10 \mathrm{~cm}$ de comprimento, $7 \mathrm{~mm}$ de diâmetro, cortes em bisel na base e reto no ápice, e remoção das folhas. Posteriormente, as estacas foram tratadas com ácido indolbutírico, nas concentrações de: 500, I.000, 2.000, 3.000 e $4.000 \mathrm{mg} \mathrm{L'}$, e a testemunha foi tratada com água destilada, sendo todas submetidas a imersão por 10 segundos.

As estacas foram mantidas em bandejas plásticas, com dimensões de $35 \times 20 \times 15 \mathrm{~cm}$, contento vermiculita de grânulos finos como substrato, sendo inserido $2 / 3$ do comprimento das estacas no substrato, em posição vertical.

O delineamento experimental adotado foi o inteiramente casualizado (DIC), com seis tratamentos $(0$, $500,1.000,2.000,3.000$ e $4.000 \mathrm{mg} \mathrm{L}^{-1}$ de AIB), quatro repetições e cinco estacas por unidade experimental (bandeja), totalizando 120 estacas.

Após 60 dias da implantação do experimento, foram analisadas as seguintes variáveis: percentagens de sobrevivência e de enraizamento das estacas, número de raízes e comprimento da maior raiz.

Os dados relativos à sobrevivência e enraizamento das estacas foram submetidos à análise de variância e as médias foram comparadas pelo teste de Tukey, com $\alpha=0,05$. As variáveis, número de raízes e comprimento da maior raiz, foram avaliadas por meio de estatísticas descritivas (média e desvio padrão).

\section{Resultados e Discussões}

As estacas de $R$. erythrocladus tratadas com $1.000 \mathrm{mg} \mathrm{L}^{-1}$ de AIB apresentaram as maiores percentagens de sobrevivência e de enraizamento, diferindo estatisticamente dos demais tratamentos (Tabela I). Resultados similares foram observados por Maia e Botelho (2008), que obtiveram 60\% de enraizamento em estacas caulinares de amora-preta cv. Xavante, porém com $2.000 \mathrm{mg} \mathrm{L}^{-1}$ de AIB. Na ausência de hormônio, Villa et al. (2003) observaram 62,38\% de enraizamento em estacas lenhosas de amora-preta Bazos.

\section{Tabela I - Percentagens de sobrevivência e enraizamento das estacas caulinares de Rubus erythrocladus em diferentes} concentrações de AIB, após 60 dias da implantação do experimento.

\begin{tabular}{ccc}
\hline Concentração de AlB $\left(\mathrm{mg} \mathrm{L}^{-1}\right)$ & Sobrevivência (\%) & Enraizamento (\%) \\
\hline 0 & $0,0 \mathrm{~b}$ * & $0,0 \mathrm{~b}$ \\
500 & $5,0 \mathrm{~b}$ & $5,0 \mathrm{~b}$ \\
1.000 & $60,0 \mathrm{a}$ & $60,0 \mathrm{a}$ \\
2.000 & $5,0 \mathrm{~b}$ & $0,0 \mathrm{~b}$ \\
3.000 & $0,0 \mathrm{~b}$ & $0,0 \mathrm{~b}$ \\
4.000 & $0,0 \mathrm{~b}$ & $0,0 \mathrm{~b}$ \\
\hline $\mathrm{CV}(\%)$ & 49,5 & 37,7 \\
\hline
\end{tabular}

* Médias seguidas pela mesma letra não diferem significativamente entre si, pelo teste de Tukey, com $\boldsymbol{\alpha}=0,05$.

Apenas as concentrações 500 e $1.000 \mathrm{mg} \mathrm{L}^{-1}$ de AlB apresentaram enraizamento, porém na concentração $1.000 \mathrm{mg} \mathrm{L}^{-1}$ de AIB foram observados os melhores resultados tanto para o número de raízes como para o comprimento da maior raiz (Tabela 2). Para a variável número de raízes, os resultados obtidos neste estudo foram superiores aos registrados para estacas caulinares de $R$. rosifolius J. Smith $(0,9)$ (Patto 20I3), porém foram inferiores aos obtidos para amora-preta cv. Xavante (22,9) (Maia e Botelho 2008) e para R. fruticosus L. $(8,28)$ por Tadeu et al. $(20 / 2)$. 
Tabela 2 - Número de raízes e comprimento da maior raiz (média \pm desvio padrão) das estacas caulinares de Rubus erythrocladus, em diferentes concentrações de AIB, após 60 dias da implantação do experimento.

\begin{tabular}{ccc}
\hline Concentração de AlB $\left(\mathrm{mg} \mathrm{L}^{-1}\right)$ & Número de raízes & Comprimento da maior raiz $(\mathrm{cm})$ \\
\hline 0 & 0,0 & 0,0 \\
500 & 1,0 & 2,0 \\
1.000 & $2,8 \pm 2,6$ & $6,5 \pm 2,5$ \\
2.000 & 0,0 & 0,0 \\
3.000 & 0,0 & 0,0 \\
4.000 & 0,0 & 0,0 \\
\hline
\end{tabular}

A concentração de $1.000 \mathrm{mg} \mathrm{L}^{-1}$ AIB causou efeito benéfico na rizogênese das estacas caulinares lenhosas de R. erythrocladus. Conforme Ono e Rodrigues (1996), o maior grau de lignificação encontrado em estacas lenhosas está correlacionado negativamente com a auxina, uma vez que enzimas, como as peroxidases, estão envolvidas tanto na síntese de lignina como na degradação de auxina. Portanto, a utilização de auxina exógena (AIB) influencia positivamente o enraizamento de estacas lenhosas, visto que apresentam baixos níveis de auxina endógena (BASTOS, 2002).

Apesar da utilização de AIB potencializar o enraizamento de estacas de espécies de Rubus, esta não foi eficiente para algumas espécies ou variedades, como: amora-preta Bazos (VILLA et al., 2003), $R$. fruticosus (TADEU et al., 20I2), $R$. rosifolius (PATTO, 20I3), R. niveus Thunb. (framboesa-negra) (VILLA et al., 20I8) e amora-preta cv. Xavante (Rubus sp.) (YAMAMOTO et al., 20I3).

Conforme Villa et al. (2003), a aplicação de AIB em estacas de Rubus pode causar efeito positivo ou negativo na rizogênese em razão das diferenças genéticas existentes entre as espécies do gênero. Segundo esses autores, estas diferenças estão relacionadas a produção endógena de auxina pelas plantas. Portanto, em materiais que produzem alta quantidade de auxina endógena a aplicação exógena deste hormônio causa efeito fitotóxico nas estacas, enquanto em materiais que apresentam baixa produção de auxina endógena a aplicação exógena promove efeitos positivos.

A auxina estimula a divisão celular, induzindo morfogênese e consequentemente a emissão de raízes adventícias. Porém, este fito-hormônio é tóxico quando usado em concentrações elevadas (TAIZ et al., 20I7). Logo, é necessário utilizar concentrações adequadas de auxinas para promover a rizogênese em estacas.

É possível que as estacas caulinares lenhosas da espécie $R$. erythrocladus apresentem quantidades de auxina endógena insuficientes para promover o enraizamento, sendo necessário o uso de AIB. A concentração de $1.000 \mathrm{mg} \mathrm{L}^{-1}$ foi a mais eficiente para a espécie avaliada. Doses abaixo desse valor indicam quantidade insuficiente de auxina para enraizamento e doses acima causaram efeito fitotóxico. $O$ tratamento com AIB, geralmente promove o aumento da percentagem de enraizamento quando utilizado em estacas, acelerando desta forma a iniciação radicular, aumentando o número e a qualidade de raízes (FACHINELLO et al., 1995).

Os resultados obtidos neste estudo mostram dificuldades na propagação de $R$. erythrocladus, porém são superiores a outras amoras silvestres nativas. Em $R$. fruticosus o enraizamento foi de $38 \%$ (TADEU et al., 20I2) e em $R$. rosifolius de 29,5\% (PATTO, 20I3).

\section{Considerações Finais}

A concentração $1.000 \mathrm{mg} \mathrm{L}^{-1}$ apresentou maior percentagem de enraizamento das estacas caulinares (60\%), maior número e maior comprimento das raízes, sendo indicada para uso. Os resultados obtidos podem ser considerados bons, devido às dificuldades na propagação por estaquia no gênero Rubus. Além disso, os resultados foram similares a outras espécies e variedades já cultivadas do mesmo gênero.

É necessária a continuidade de estudos com propagação por meio de estaquia de $R$. erythrocladus, visando aperfeiçoar o protocolo para a espécie. 


\section{Referências}

ANTUNES, L. E.; RASEIRA, M. C. B. Aspectos técnicos da cultura da amora-preta. Pelotas: Embrapa Clima Temperado, 2004.

BARCELOS, L. B.; HEIDEN, G. Distribuição geográfica de espécies de amora (Rubus, Rosaceae) nativas do brasil. In: XXIV CONGRESSO DE INICIAÇÃO CIENTÍFICA DA UNIVERSIDADE FEDERAL DE PELOTAS, 2015, Pelotas, RS. Anais [...]. Pelotas: UFPEL, 2015.

BASTOS, D. C. Efeito da época de coleta, estádio do ramo e do tratamento com IBA no enraizamento de estacas de caramboleira (Averrhoa carambola L.). Dissertação (Mestrado em Agronomia) - Faculdade de Ciências Agrárias e Veterinárias, Universidade Estadual Paulista, Jaboticabal, 2002.

BUENO, P. M. C., BIASI, L. A.; TOFANELLI, M. B. D. Micropropagation protocol for the wild Brazilian greenberry (Rubus erythroclados). Revista Colombiana de Ciencias Hortícolas, v. I2, n. 2, p. 405-4I5, 2018.

CARPANEZZI, A. A.; ZANONA, K.; VOLTZ, R. R. Separação botânica de espécies de Rubus da Região Metropolitana de Curitiba. Colombo: Embrapa Florestas, 2019.

DEIGHTON, N.; BRENNAN, R.; FINN, C.; DAVIES, H. V. Antioxidant properties of domesticated and wild Rubus species. Journal of the Science of Food and Agriculture, v. 80, p. 1307-1313, 2000.

FACHINELLO, J. C.; HOFFMANN, A.; NACHTIGAL, J. C.; KERSTEN, E.; FORTES, G. R. de L. Propagação de plantas frutíferas de clima temperado. Pelotas: Editora e Gráfica UFPel, 1995.

HAN, H; ZHANG, S; SUN, X. A review on the molecular mechanism of plants rooting modulated by auxin. African Journal of Biotechnology, v. 8, p. 348-353, 2009.

HUANG, J. Y.; HU, J. M. Revision of Rubus (Rosaceae) in Taiwan. Taiwania, v. 54, n. 4, p. 285-310, 2009.

HUE, S. M. Delícias do descobrimento: a gastronomia brasileira no século XVI. Rio de Janeiro: Jorge Zahar, 2008.

HUMMER, K. E. Rubus Pharmacology: Antiquity to the Present. HortScience, v. 45, p. 1587-159I, 2010.

KINUPP, V. F.; LORENZI, H. Plantas Alimentícias Não Convencionais (PANC) no Brasil: guia de identificação, aspectos nutricionais e receitas ilustradas. São Paulo: Instituto Plantarum, 2014.

MAIA, A. J.; BOTELHO, R. V. Reguladores vegetais no enraizamento de estacas lenhosas da amoreira-preta cv. Xavante. Ciências Agrárias, v. 29, p. 323-330, 2008.

ONO, E. O.; RODRIGUES, J. D. Aspectos da fisiologia do enraizamento de estacas caulinares. Jaboticabal: FUNEP, $1996.83 \mathrm{p}$.

PATTO, L. S. Armazenamento a frio e fitorreguladores na propagação vegetativa da amoreira vermelha (Rubus rosifolius). Dissertação (Mestrado em Fitotecnia) - Universidade Federal de Lavras, Lavras, 2013.

PIO CORRÊA, M. Dicionário das plantas úteis do Brasil e das exóticas cultivadas. Rio de Janeiro: Imprensa Nacional, 1984.

REITZ, R.; KLEIN, R. M. Rosáceas. Itajaí: Herbário Barbosa Rodrigues, 1996.

SIMÃO-BIANCHINI, R. Rosaceae in Lista de Espécies da Flora do Brasil. Rio de Janeiro: Jardim Botânico do Rio de Janeiro, 2015. Disponível em: http://floradobrasil.jbrj.gov.br/jabot/floradobrasil/FB32508. Acesso em: 23 jul. 2019.

TADEU, M. H.; PIO, R.; TIBERTI, A. S.; FIGUEIREDO, M. A. de; SOUZA, F. B. M. de. Enraizamento de estacas caulinares e radiculares de Rubus fruticosus tratadas com AIB. Revista Ceres, v. 59, p. 88I-884, 2012.

TAIZ, L.; ZEIGER, E.; MOLLER, I.; MURPHY, A. Fisiologia e desenvolvimento vegetal. Porto Alegre: Artmed, 2017.

TALLINI, L. R.; PEDRAZZA, G. P. R.; BORDIGNONB, S. A. L.; COSTAC, A. C. O.; STEPPE, M.; FUENTEFRIA, A.; ZUANAZZI, J. A. S. Analysis of flavonoids in Rubus erythrocladus and Morus nigra leaves extracts by liquid chromatography and capillary electrophoresis. Revista Brasileira de Farmacognosia, v. 25, p. 219-227, 2015.

VILLA, F; PIO, R.; CHALFUN, N. N. J.; GONTIJO, T. C. A.; DUTRA, L. F. Propagação de amoreira-preta utilizando estacas lenhosas. Ciência e Agrotecnologia, v. 27, p. 829-834, 2003.

VILLA, F.; STUMM, D. R.; SILVA, D. F. da; MENEGUSSO, F. J.; RITTER, G.; KOHLER, T. R. Rooting of black raspberry with plant growth regulator. Ciência Rural, v. 48, n. 3, 2018.

YAMAMOTO, L. Y.; KOYAMA, R.; BORGES, W. F. S.; ANTUNES, L. E. C.; ASSIS, A. M. de; ROBERTO, S. R. Substratos no enraizamento de estacas herbáceas de amora-preta Xavante. Ciência Rural, v. 43, p. 15-20, 2013. 